\title{
Antioxidant activities of crude extracts from peel and seed of Cinnamomum camphora.
}

\author{
Chi-Ming Liu", Mei-Hui Perng ${ }^{2 *}$, Chung-Yi Chen ${ }^{3^{*}}$ \\ ${ }^{1}$ School of Medicine, Yichun University, Yuanzhou District, Yichun, Jiangxi Province, PR China \\ ${ }^{2}$ Department of Health Beauty, Fooyin University, Kaohsiung, Taiwn \\ ${ }^{3}$ Department of Nutrition and Health Science, School of Medical and Health Sciences, Fooyin University, Ta-Liao \\ District, Kaohsiung, Taiwan
}

\begin{abstract}
In this study, we aim to investigate the free radical scavenging, anti-melanogenic and antibacterial properties of crude extracts from peel and seed of Cinnamomum camphora. Results showed that methanol extract of peel was minor sensitive to Staphylococcus aureaus and Escherichia coli. The fractions obtained by n-hexane, ethyl acetate (EtOAc), n-butanol or water of peel and seed had significant antioxidant activity. The $\mathrm{IC}_{50}$ value of n-butanol, water and ethyl acetate fraction of the peel exhibited 48.82, 221.32 and $647.85 \mu \mathrm{g} / \mathrm{ml}$ scavenging activity in DPPH free radical. The $\mathrm{IC}_{50}$ value of $\mathrm{n}$ butanol, water and ethyl acetate fraction of the peel exhibited $1135.47,438.69$ and $3127.09 \mu \mathrm{g} / \mathrm{ml}$ in metal chelating ability on ferrous ions assays. $n$-butanol fraction of peel displayed the best antioxidant activity in ABTS assay. Especially, $\mathrm{IC}_{50}$ of the mushroom tyrosinase inhibition at $n$-hexane extraction of the seed was $53.68 \mu \mathrm{g} / \mathrm{ml}$. The results obtained in the present investigation suggest that the crude extracts of peel and seed of $C$. camphora had promising antibacterial and antioxidant activity against free radicals. The n-butanol or water extract of peel may be further study to isolate the active compounds in the future.
\end{abstract}

Keywords: Cinnamomum camphora, Antioxidant activity, Mushroom tyrosinase inhibition, Antibacterial efficiency. Accepted on June 25, 2018

\section{Introduction}

Oxidants such as nitric monoxide $\left(\mathrm{NO}{ }^{\circ}\right)$, superoxide $\left(\mathrm{O}_{2}^{-}\right)$and hydroxyl $\left(\mathrm{OH}^{\bullet}\right)$ are free radicals. Hydroxyl radicals, superoxides, and hydroperoxides are ROS (Reactive Oxygen Species) with characteristics according their reactivity. ROS is associated with cancer, diabetes, obesity and chronic inflammation [1-3]. The excess of ROS is harmful to cells and tissues. ROS can produce oxidative damage to lipid, proteins and DNA in living bodies and cause many chronic diseases such as cancer and diabetics. These diseases can be cured or slowed down by using natural or synthetic compounds. It is widely known that fruits and vegetables have potential to reduce the risk of oxidative stress related diseases. Antioxidants such as vitamins A, C, E and phytochemicals can prevent ROS production [4-6].

Ultraviolet ray (UV) is harmful to human health particularly in skin. UV stimulates tyrosinase activity and accelerates the dark spot formation [7,8]. Melanin plays an important role against UV in human skin. Tyrosinase is the rate-limiting enzyme in melanin formation. Inhibition of melanin can reduce melanin pigments in the skin tissue. A lot of pharmaceutical companies are searching novel compounds in preventing UV irritation
[7,9]. Studies have shown that some phytochemicals such as caffeic acid and ferulic acid have tyrosinase inhibition [10,11].

Cinnamomum camphora is also known as camphor tree and native to China, Taiwan and Japan. C. camphora belonged to Lauraceae family. C. camphora has been used in tradition use such as bronchitis, asthma, indigestion and inflammationrelated diseases. The previous studies have shown that $C$. camphora contains alkaloids and essential oil such as camphor and type II ribosome-inactivating proteins [12-15]. A study reported $C$. camphora extracts has anti-inflammatory and antioxidative effects [16]. The details mechanisms of the antiinflammatory activity and active components, however, remain further examine.

Multidrug-Resistant (MDR) bacterial is a serious problem in the antibacterial therapy. $\beta$-lactamase-producing Escherichia coli, carbapenem-resistant Enterobacteriaceae, Acinetobacter baumannii, and methicillin-resistant Staphylococcus aureus (MRSA) are well known MDR bacterial in the world [17,18]. The therapeutic options for these pathogens are extremely limited. Researchers are searching the effective alternatives in the treatment of MDR bacterial. The phytochemicals for 
antimicrobial therapy in vitro have been reported with pharmacological activities [19].

In the present work were studied the various extracts (nhexane, water, methanol, compression, n-butanol and acetyl acetate) from different parts (seed and peel) of C. camphora in anti-melanogenic, antibacterial and anti-oxidation activities.

\section{Materials and Methods}

\section{Collection of plant materials}

The peel and seed of C. camphora were collected from Chiayi County, Taiwan, May 2009. Plant material was identified by Professor Fu-Yuan Lu (Department of Forestry and Natural Resources, College of Agriculture, National Chiayi University). A voucher specimen was deposited in the School of Medicial and Health Sciences, Fooyin University, Kaohsiung City, Taiwan.

\section{Extraction and fractionation}

In this study, we used four C. camphora organic solvent extracts. The air-dried peels of $C$. camphora $(0.4,0.6,0.4,0.5$ $\mathrm{kg}$ ) were extracted with n-butanol, $\mathrm{MeOH}, \mathrm{H}_{2} \mathrm{O}$ and EA $(5 \mathrm{~L} \times$ 5) at room temperature, respectively. The extracts from nbutanol, $\mathrm{MeOH}, \mathrm{H}_{2} \mathrm{O}$ and EA were 32.8, 29.7, 22.7 and $64.9 \mathrm{~g}$ through concentration under reduced pressure. The air-dried seeds of C. camphora $(1.1 \mathrm{~kg})$ were extracted with n-hexane (4 $\mathrm{L} \times 3)$ at room temperature and the extract $(42.5 \mathrm{~g})$ concentrated under reduced pressure.

\section{Test organisms and culture preparation}

The bacterial and fungus strains of Escherichia coli (ATCC 605) and Staphylococcus aureus (ATCC 25923) were obtained from American Type Culture Collection. All the test organisms were grown in nutrient broth for overnight at $37^{\circ} \mathrm{C}$ separately before performing assays.

\section{Determination of antibacterial assay disc diffusion method}

The antibacterial activity of extracts of the seed was analysed by disc diffusion method. Nutrient agar was prepared, sterilized by autoclaving and poured into the sterile petri plates. After solidification, the plates were swabbed with test organism $\left(10^{9} \mathrm{CFU} / \mathrm{ml}\right)$ by using sterile cotton swabs. Sterile paper discs of $8 \mathrm{~mm}$ diameter were concentrated with $40 \mu \mathrm{l}$ of all extracts and air dried. The discs were placed on the surface of the nutrient agar plates and inoculated with test organisms. All the plates were incubated at $37^{\circ} \mathrm{C}$ for $48 \mathrm{~h}$ and the zone of inhibition was measured at the end of incubation period.

\section{Metal chelating activity}

Briefly, various different concentrations of $1 \mathrm{ml}$ of samples were dissolved in DMSO and added to a solution of $0.05 \mathrm{ml}$ of $2 \mathrm{mM} \mathrm{FeCl}_{2} \bullet 4 \mathrm{H}_{2} \mathrm{O}$. The reaction was initiated by addition 0.02 $\mathrm{ml}$ of $5 \mathrm{mM}$ ferrozine. The mixture was vigorously shaken and incubated at room temperature for $10 \mathrm{~min}$. The absorbance of the test sample was then measured at $562 \mathrm{~nm}$. The metal chelating activity was determined as: 1-( $\left(\mathrm{A}_{\text {control }}-\mathrm{A}_{\text {sample }}\right) /$ $\left.\mathrm{A}_{\text {control }}\right) \times 100 \%$. EDTA was used as a positive control. The amount of inhibition by the test samples was expressed as the percentage of concentration necessary to achieve $50 \%$ inhibition $\left(\mathrm{IC}_{50}\right)$.

\section{Assay on mushroom tyrosinase activity}

The test sample was dissolved in DMSO $(60 \mu \mathrm{L})$ with $50 \mathrm{mM}$ phosphate buffer (pH 6.8, $70 \mu \mathrm{L}$ ) and $125 \mathrm{U} / \mathrm{ml}$ of mushroom tyrosinase $(10 \mu \mathrm{L})$. L-tyrosine $(0.3 \mathrm{mg} / \mathrm{ml}, 70 \mu \mathrm{L})$ was added in the same buffer and incubated at $37^{\circ} \mathrm{C}$ for $30 \mathrm{~min}$. The assays were conducted in a 96-well microplate and absorbance was determined at $490 \mathrm{~nm}$. Percent inhibition of tyrosinase activity was calculated as the following equation: \% tyrosinase inhibition $=100 \% \times((\mathrm{A}-\mathrm{B})-(\mathrm{C}-\mathrm{D})) /(\mathrm{A}-\mathrm{B})$ where $\mathrm{A}$ is blank solution with tyrosinase; $\mathrm{B}$ is blank solution without tyrosinase; $\mathrm{C}$ is the test substance with tyrosinase; and $\mathrm{D}$ is test substance without tyrosinase. Kojic acid was used as a positive control. The amount of inhibition by the test samples was expressed as the percentage of concentration necessary to achieve $50 \%$ inhibition $\left(\mathrm{IC}_{50}\right)$.

\section{Determination of DPPH radical scavenging capacity}

Briefly, various concentrations $0.2 \mathrm{ml}$ of the samples were added to $3.8 \mathrm{ml}$ of stable DPPH solution (final concentration, $0.1 \mathrm{mM}$ ). The mixture was vortexed for $1 \mathrm{~min}$ and incubated at room temperature in the dark for $30 \mathrm{~min}$. The absorbance for test sample was measured at $517 \mathrm{~nm}$. The analysed time interval was $10 \mathrm{~min}$ per point up to $30 \mathrm{~min}$. Catechin was used as a positive control in this experiment. The $\mathrm{DPPH}^{\bullet}$ radical discolouration of the sample was determined as: (1- $\left(\mathrm{A}_{\text {sample }} /\right.$ $\left.\left.\mathrm{A}_{\text {control }}\right)\right) \times 100$. The amount of inhibition by the test samples was expressed as the percentage of concentration necessary to achieve $50 \%$ inhibition $\left(\mathrm{IC}_{50}\right)$.

\section{ABTS radical scavenging assay}

The stock solution of ABTS is $7 \mathrm{mM}$ and potassium persulfate is $2.45 \mathrm{mM}$. The two stock solutions were mixed equal volume and incubated overnight at room temperature in the dark. The working solution was then diluted with methanol to obtain an absorbance of $0.706 \pm 0.01$ units at $745 \mathrm{~nm}$. The test samples were reacted with $1 \mathrm{ml}$ of ABTS solution and the absorbance was measured at $745 \mathrm{~nm}$ after $7 \mathrm{~min}$ by double beam spectrophotometer. Results are presented as the ability of test samples was determined against a standard calibration curve TEAC (Trolox equivalent antioxidant capacity) and expressed as $\mu \mathrm{M}$.

\section{Statistical analysis}

All data are the means \pm SD from at least triplicate experiments. 


\section{Results}

\section{In vitro antimicrobial activity}

The antibacterial activity of different spices used in this study is given in Table 1. The methanol extraction of camphor tree peel showed minor activity against the tested microorganisms compared with ampicillin by the disc diffusion method (Figure 1). The positive control ampicillin was extremely effective on Escherichia coli and Staphylococcus aureus with inhibition zones ranging from 9.04 to $8.66 \mathrm{~mm}$. The antibacterial activity of methanol extraction showed more effective on Staphylococcus aureus than on Escherichia coli.

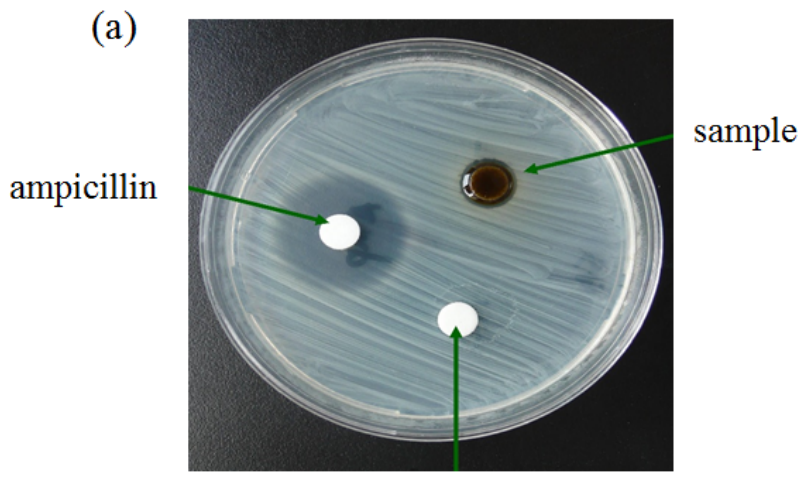

Methanol (negative control)

Figure 1. The antibacterial activity of $\mathrm{MeOH}$ extraction of $\mathrm{C}$. camphora (peel) on Staphylococcus aureus (a) and Escherichia coli (b).

\section{Antioxidant activities and mushroom tyrosinase inhibition of extracts and fractions from $C$. camphora}

Table 1 showed the total antioxidant activity of different extractions expressed as TEAC (Trolox equivalent antioxidant capacity). The results indicated the compression and n-hexane fraction from the seed were barely detected antioxidant activity. 1-butylalcohol fraction of peel displayed the best antioxidant activity.

In the DPPH assay, antioxidants are able to reduce the stable DPPH radicals at room temperature. Results showed that 1butylalcohol fraction of peel displayed the best radical scavenging activity. The $\mathrm{IC}_{50}$ values of 1-butylalcohol, water, ethyl acetate extraction of peel were $48.82 \pm 4.32,221.32 \pm$ $7.63,648.75 \pm 5.48 \mu \mathrm{g} / \mathrm{ml}$ in the DPPH assay (Table 2).

The ferrous ion chelating activities of different fractions of the peel were shown in Table 2 . Ferrozine quantitatively produced complexes with $\mathrm{Fe}^{2+}$. Water extraction of peel of $\mathrm{Fe}^{2+}$ showed best scavenging effect. EDTA is the positive control. The $\mathrm{IC}_{50}$ values of 1-butylalcohol, water, ethyl acetate fraction of peel were $1135.47 \pm 10.32,438.69 \pm 7.83,3127.09 \pm 9.87 \mu \mathrm{g} / \mathrm{ml}$, in the chelating assay.

Further, the inhibitory effect of different fractions of seed was determined in an in vitro mushroom tyrosinase inhibition assay (Table 2). Kojic acid $t$ is a commonly used as a positive control. Compression and n-hexane fraction of the seed showed inhibition in mushroom tyrosinase inhibition assay. The $\mathrm{IC}_{50}$ values of compression and $\mathrm{n}$-hexane fraction were $83.52 \pm 6.84$ and $53.68 \pm 7.30 \mu \mathrm{g} / \mathrm{ml}$.

Table 1. Antibacterial activity of $\mathrm{MeOH}$ extract of $\mathrm{C}$. camphora (peel), ampicillin and methanol after $48 \mathrm{~h}$ treatment.

\begin{tabular}{|c|c|c|c|}
\hline \multirow[t]{3}{*}{ Pathogens } & \multicolumn{3}{|c|}{ Inhibition diameter (mm) } \\
\hline & \multicolumn{3}{|c|}{ Including disk diameter of $8.0 \mathrm{~mm}$} \\
\hline & Peel & Ampicillin & Methanol \\
\hline $\begin{array}{l}\text { Staphylococcus } \\
\text { aureus }\end{array}$ & $8.18 \pm 0.08$ & $9.04 \pm 0.11$ & $8.00 \pm 0$ \\
\hline Escherichia coli & $8.11 \pm 0.03$ & $8.66 \pm 0.30$ & $8.00 \pm 0$ \\
\hline
\end{tabular}

Table 2. Antioxidant and anti-tyrosinase properties of different extracts.

\begin{tabular}{|c|c|c|c|c|c|}
\hline Fraction & & Mushroom tyrosinase $(\mu \mathrm{g} / \mathrm{ml})$ & DPPH $(\mu \mathrm{g} / \mathrm{ml})$ & Chelating $(\mu \mathrm{g} / \mathrm{ml})$ & ABTS $(\mu M)$ \\
\hline \multirow[t]{2}{*}{ Seed } & n-hexane & $53.68 \pm 7.3$ & 0 & 0 & $0.03 \pm 0.001$ \\
\hline & compression & $83.52 \pm 6.84$ & 0 & 0 & 0 \\
\hline \multirow[t]{3}{*}{ Peel } & n-butanol & - & $48.82 \pm 4.32$ & $1135.47 \pm 10.32$ & $13.20 \pm 1.32$ \\
\hline & $\mathrm{H}_{2} \mathrm{O}$ & - & $221.32 \pm 7.63$ & $438.69 \pm 7.83$ & $5.87 \pm 0.87$ \\
\hline & ethyl acetate & - & $647.85 \pm 5.48$ & $3127.09 \pm 9.87$ & $2.79 \pm 0.24$ \\
\hline Kojic acid & & $47.39 \pm 3.82$ & - & - & - \\
\hline EDTA & & - & - & $1.39 \pm 0.05$ & - \\
\hline Catechin & & - & $3.94 \pm 0.02$ & - & - \\
\hline
\end{tabular}

Data were expressed as a mean value of at least three independent experiments. Catechin was used as a positive control on DPPH assay; EDTA was used as a positive control on metal chelating; Kojic acid was used as a positive control of mushroom tyrosinase assay; - means no test. 


\section{Discussion}

Traditional Chinese Medicine (TCM) has many bioactive substances including polyphenol and anthocyanins compounds with anti-oxidation and anti-inflammation effects [20]. It is well known that antioxidants are free radical scavengers. Free radicals are produced in several oxidative-reductive processes and free radicals may involve chronic diseases such as cancer and heart disease. Antioxidants neutralize free radicals, thus preventing them from causing damage. Antioxidants act through different possible mechanisms. In this study, we evaluated the extracts of antioxidant capacity by DPPH, metal chelating and ABTS assays. The antioxidant capacity of different plants gives the plant their significant nutritional and therapeutic values [21]. In this study, we found that the extracts from seed did not have antioxidation activity by compression and n-hexane extraction. These results indicated that the antioxidation activity mainly comes from the peel. While the water or n-butanol fraction of peel displayed the better antioxidant activity than ethyl acetate fraction.

Tyrosinase is produced only by melanocyte cells. Tyrosinase plays an important role in controlling melanogenesis. The extracts and isolated compounds from plants have tyrosinase inhibition. Agents or products that inhibit tyrosinase activity have been used in skin whitening cosmetics. Hydroquinone, arbutin, kojic acid, azelaic acid and L-ascorbic acid have tyrosinase inhibition as skin whitening agents [22-24]. In this study, we found that n-hexane extraction and compression of the seed has tyrosinase inhibition. We think the bioactive components could be degraded at high temperature in compression method.

Although a lot of in vitro studies demonstrate that extracts have antibacterial activity. In the current study, methanol extract from peel was minor sensitive to Staphylococcus aureus and Escherichia coli. The antibacterial activity is depending on the chemical composition, extraction and bacterial strains tested. At least, the current study indicated that methanol extract from peel exhibited limited antibacterial activity.

There are many ongoing studies for developing synthetic antioxidant compounds. Previous study has demonstrated that C. camphora total extractions displayed anti-inflammatory actions because of the modulation of cytokine, NO and PGE2 production and oxidative stress [16]. Additionally, camphor and camphor oil are an important source for perfume in this plant. Camphor also displays a lot of biological properties such as insecticidal and antimicrobial activities. Studies have shown essential oils from $C$. camphora aerial parts and stem barks displayed insecticidal activities. Few studies discussed the biological and pharmacological properties of C. camphora extracts from the seed and peel. In this study, we compared various fractions of seed and peel of Cinnamomum camphora in anti-melanogenic, antioxidation and antibacterial activity.

\section{Conclusion}

In this study, we first demonstrated different crude extracts of peel and seed of C. camphora displayed antioxidation, anti- melanogenic and antibacterial activity. In the future, it is necessary to further isolate the active constituents and determine their pharmacological effects.

\section{Acknowledgements}

This investigation was supported by a grant from the Fooyin University.

\section{References}

1. Farinati F, Piciocchi M, Lavezzo E, Bortolami M, Cardin R. Oxidative stress and inducible nitric oxide synthase induction in carcinogenesis. Dig Dis 2010; 28: 579-584.

2. Pitocco D, Zaccardi F, Di Stasio E, Romitelli F, Santini SA, Zuppi C, Ghirlanda G. Oxidative stress, nitric oxide, and diabetes. Rev Diabet Stud 2010; 7: 15-25.

3. Reuter S, Gupta SC, Chaturvedi, M. M, Aggarwal, B. B, Oxidative stress, inflammation, and cancer: how are they linked? Free Radic Biol Med 2010; 49: 1603-1616.

4. Chen PY, Ho YR, Wu MJ, Huang SP, Chen PK, Tai MH, Ho CT, Yen JH. Cytoprotective effects of fisetin against hypoxia-induced cell death in PC12 cells. Food Funct 2015; 6: 287-296.

5. Deguchi A. Curcumin targets in inflammation and cancer. Endocr Metab Immune Disord Drug Targets 2015; 15: 88-96.

6. Lu B, Li M, Yin R. Phytochemical content, health benefits, and toxicology of common edible flowers: a review (2000-2015). Crit Rev Food Sci Nutr 2016; 56: 130-148.

7. Pillaiyar T, Manickam M, Namasivayam V. Skin whitening agents: medicinal chemistry perspective of tyrosinase inhibitors. J Enzyme Inhib Med Chem 2017; 32: 403-425.

8. Mohania D, Chandel S, Kumar P, Verma V, Digvijay K, Tripathi D, Choudhury K, Mitten SK, Shah D. Ultraviolet radiations: skin defense-damage mechanism. Adv Exp Med Biol 2017; 996: 71-87.

9. Chen YH, Huang L, Wen ZH, Zhang C, Liang CH, Lai ST, Luo LZ, Wang YY, Wang, GH. Skin whitening capability of shikimic acid pathway compound. Eur Rev Med Pharmacol Sci 2016; 20: 1214-1220.

10. Perez-Sanchez A, Barrajon-Catalan E, Herranz-Lopez M, Castillo J, Micol V. Lemon balm extract (Melissa officinalis, L.) promotes melanogenesis and prevents UVB-induced oxidative stress and DNA damage in a skin cell model. J Dermatol Sci 2016; 84: 169-177.

11. Ambothi K, Prasad NR, Balupillai A. Ferulic acid inhibits UVB-radiation induced photocarcinogenesis through modulating inflammatory and apoptotic signaling in Swiss albino mice. Food Chem Toxicol 2015; 82: 72-78.

12. Tomita M, Kozuka M. on the Alkaloids of Cinnamomum Camphora (Linn.) Sieb. Yakugaku Zasshi 1964; 84: 365-367.

13. Hayashi S, Yano K, Matsuura T. Two phenol ethers and an aliphatic ketone of the essential oil of the Kusunoki 
(Cinnamomum camphora, Sieb.). Bull Chem Soc Jpn 1969; 42: 3591.

14. He WJ, Liu WY. Cinnamomin: a multifunctional type II ribosome-inactivating protein. Int $\mathrm{J}$ Biochem Cell Biol 2003; 35: 1021-1027.

15. Liu RS, Wei GQ, Yang Q, He WJ, Liu WY. Cinnamomin, a type II ribosome-inactivating protein, is a storage protein in the seed of the camphor tree (Cinnamomum camphora). Biochem J 2002; 362: 659-663.

16. Lee HJ, Hyun EA, Yoon WJ, Kim BH, Rhee MH, Kang HK, Cho JY, Yoo ES. In vitro anti-inflammatory and antioxidative effects of Cinnamomum camphora extracts. J Ethnopharmacol 2006; 103: 208-216.

17. Avery LM, Nicolau DP. Investigational drugs for the treatment of infections caused by multidrug-resistant Gram-negative bacteria. Expert Opin Investig Drugs 2018; 27: 325-338.

18. Karaiskos I, Giamarellou H. Multidrug-resistant and extensively drug-resistant Gram-negative pathogens: current and emerging therapeutic approaches. Expert Opin Pharmacother 2014; 15: 1351-1370.

19. Simoes $M$, Bennett RN, Rosa EA. Understanding antimicrobial activities of phytochemicals against multidrug resistant bacteria and biofilms. Nat Prod Rep 2009; 26: 746-757.

20. Ye H, Shi ZM, Chen Y, Yu J, Zhang XZ. Innovative perspectives of integrated Chinese medicine on $\mathrm{H}$. pylori. Chin J Integr Med 2018.

21. Taleb A, Ahmad KA, Ihsan AU, Qu J, Lin N, Hezam K, Koju N, Hui L, Qilong D. Antioxidant effects and mechanism of silymarin in oxidative stress induced cardiovascular diseases. Biomed Pharmacother 2018; 102: 689-698.

22. Desmedt B, Courselle P, De Beer JO, Rogiers V, Grosber M, Deconinck E, De Paepe K. Overview of skin whitening agents with an insight into the illegal cosmetic market in Europe. J Eur Acad Dermatol Venereol 2016; 30: 943-950.

23. Zhang L, Tao G, Chen J, Zheng ZP. Characterization of a new flavone and tyrosinase inhibition constituents from the twigs of Morus alba L. Molecules 2016; 21: 1130.

24. Sima VH, Patris S, Aydogmus Z, Sarakbi A, Sandulescu R, Kauffmann JM. Tyrosinase immobilized magnetic nanobeads for the amperometric assay of enzyme inhibitors: application to the skin whitening agents. Talanta 2011; 83: 980-987.

\section{*Correspondence to}

Chung-Yi Chen

Department of Nutrition and Health Science

School of Medical and Health Sciences

Fooyin University

Taiwan

Mei-Hui Perng

Department of Health Beauty

Fooyin University

Taiwan 